\title{
Audit Tingkat Kematangan Proses Internal Key Logistics System Menggunakan Kerangka Kerja Cobit 4.1 Pada Perusahaan Ekspedisi XYZ
}

\author{
Albaar Rubhasy ${ }^{1}$; Dewi Murti Milasari ${ }^{2}$ \\ ${ }^{1}$ Program Studi Teknik Informatika, Universitas Nasional, Jakarta \\ ${ }^{2}$ Program Studi Sistem Informasi, STMIK Indonesia, Jakarta \\ 1albaar.rubhasy@gmail.com
}

\begin{abstract}
The purpose of this study is to evaluate the level of IT maturity that occur in XYZ Shipping Company using COBIT 4.1 framework as a best practice in information technology audit. The company is highly depend on Key Logistics System as a core system in shipping process. For this reason, the company wants to focus on internal processes by increasing efficiency while minimizing costs, so COBIT IT Process was chosen: PO3, AI2, AI5, AI3, AI4, AI7, PO6, DS3, DS7, DS8, DS9, PO5, and DS6. An assessment was conducted on 26 Key Logistics System users as respondents. Stages of research to be carried out include: identification of the COBIT 4.1 process; data collection; measurement of current and target maturity levels; gap analysis; and preparation of recommendations. Result has shown that the average maturity score of the Key Logistics System is 3,50 or in maturity level 4 (managed). At this level the key logistics system process has been carried out and part of it has been standardized. However, results shows that there are some gaps below the target, such as IT Process PO5, AI2, and AI5 which have maturity level 3 (defined). In order to improve the maturity level, XYZ Shipping Company has to optimize the IT investement, application maintenance, and IT resources.
\end{abstract}

Keywords: IT Audit, internal process, COBIT 4.1, maturity level

\begin{abstract}
ABSTRAK
Tujuan dari penelitian ini adalah untuk mengevaluasi tingkat kematangan teknologi informasi pada Perusahaan Ekspedisi XYZ menggunakan kerangka kerja COBIT 4.1 sebagai best practice dalam audit teknologi informasi. Perusahaan sangat bergantung pada Key Logistics System sebagai core system dalam proses ekspedisi. Untuk itu, perusahaan ingin fokus pada proses internal dengan meningkatkan efisiensi dengan meminimalkan biaya, sehingga terpilih COBIT IT Process: PO3, AI2, AI5, AI3, AI4, AI7, PO6, DS3, DS7, DS8, DS9, PO5, dan DS6. Assessment dilakukan terhadap 26 pengguna Key Logistics System sebagai responden. Tahapan penelitian yang akan dilakukan antara lain: identifikasi proses COBIT 4.1; pengumpulan data; pengukuran tingkat kematangan saat ini dan target; analisis kesenjangan; dan penyusunan rekomendasi. Hasil diperoleh bahwa tingkat kematangan rata-rata dari Key Logistics System adalah 3,50 atau setara dengan level 4 (managed). Pada level ini, proses Key Logistics System telah berjalan dengan baik dan sebagian prosesnya sudah terstandar. Namun, terdapat kesenjangan proses yang masih berada di bawah target tingkat kematangan, yaotu proses PO5, AI2, dan AI5 yang masih berada pada level 3 (defined). Untuk memperbaiki tingkat kematangan, Perusahaan Ekspedisi XYZ harus mengoptimasi investasi TI, perawatan aplikasi, dan sumber daya TI.
\end{abstract}

Kata kunci: Audit TI, proses internal, COBIT 4.1, tingkat kematangan 
PETIR: Jurnal Pengkajian dan Penerapan Teknik Informatika

Vol. 13, No. 1, Maret 2020, P-ISSN 1978-9262, E-ISSN 2655-5018

DOI: https://doi.org/10.33322/petir.v13i1.891

\section{PENDAHULUAN}

\subsection{Latar Belakang}

Teknologi informasi saat ini berperan penting dalam bisnis dan organisasi. Melalui teknologi informasi perusahaan dapat memperoleh kemudahan dalam melakukan proses bisnis. Untuk meningkatkan eksistensi terkait dengan sistem yang ada, salah satu perkembangan yang penting adalah semakin dibutuhkannya penggunaan alat pengolah data atau aplikasi website yang berfungsi untuk menghasilkan komunikasi yang lebih akurat dari segi penerapan dan penyajian sumber data.

Teknologi informasi merupakan suatu teknologi yang digunakan untuk mengolah data, memproses, mendapatkan, menyusun dan menyimpan data dalam berbagai cara untuk menghasilkan informasi yang berkualitas, yaitu informasi yang relevan dan tepat waktu. Informasi tersebut digunakan untuk keperluan dalam kegiatan suatu perusahaan. Pemanfaatan komputer dapat menunjang penyajian informasi yang cepat, tepat, efisien serta dapat diakses oleh pengguna.

Perusahaan Ekspedisi XYZ merupakan salah satu perusahaan yang bergerak di bidang jasa ekspedisi yang telah menerapkan teknologi informasi pada seluruh proses bisnisnya. Perusahaan tersebut ingin meningkatkan proses bisnis internalnya melalui penerapan TI dengan mengimplementasikan Key Logistics System. Kerangka kerja COBIT 4.1 merupakan best practice yang disusun oleh IT Governance Institute yang dapat membantu manajemen dalam mengevaluasi tata kelola TI, khususnya pada penerapan Key Logistics System di lingkungan Perusahaan Ekspedisi XYZ. Diharapkan dengan mengetahui tingkat kematangan, manajemen dapat membenahi sistem tersebut di masa mendatang.

\subsection{Identifikasi dan Rumusan Masalah}

Beberapa permasalahan yang telah teridentifikasi antara lain:

1) Aplikasi Key Logistics System Perusahaan Ekspedisi XYZ belum sepenuhnya terintegrasi dengan sistem lain di dalam perusahaan

2) Key Logistics System belum sepenuhnya memiliki prosedur yang standar untuk menunjang proses bisnis perusahaan.

3) Biaya pemeliharaan dan manfaat yang dirasakan oleh Perusahaan Ekspedisi XYZ belum optimal dalam kontribusinya terhadap profitabilitas bisnis perusahaan.

Berdasarkan identifikasi masalah tersebut, dirumuskan permasalahan yang dijadikan sebagai fokus sebagai berikut:

1) Bagaimana tingkat kematangan Key Logistics System terhadap pada Perusahaan Ekspedisi XYZ?

2) Bagaimana hasil evaluasi Key Logistics System pada Perusahaan Ekspedisi XYZ menggunakan framework COBIT 4.1 ?

3) Bagaimana rekomendasi untuk meningkatkan penerapan Key Logistics System pada Perusahaan Ekspedisi XYZ?

\subsection{Tujuan Penelitian}

Tujuan dari penelitian ini antara lain:

1) Menilai tingkat kematangan (maturity level) pada Perusahaan Ekspedisi XYZ menurut framework COBIT 4.1.

2) Mendeskripsikan solusi Sistem Informasi Key Logistics System pada Perusahaan Ekspedisi XYZ dengan COBIT 4.1 agar bisa mendukung proses bisnis perusahaan. 
PETIR: Jurnal Pengkajian dan Penerapan Teknik Informatika Vol. 13, No. 1, Maret 2020, P-ISSN 1978-9262, E-ISSN 2655-5018 DOI: https://doi.org/10.33322/petir.v13i1.891

\subsection{Batasan Masalah}

Agar penelitian tidak menyimpang dari tujuan yang direncanakan, maka perlu ditetapkan batasan-batasan sebagai berikut:

1) Audit Key Logistics System pada Perusahaan Ekspedisi $X Y Z$ dibatasi sampai tingkat kematang pada sistem menggunakan framework COBIT 4.1.

2) Menganalisis penerapan Key Logistics System pada Perusahaan Ekspedisi XYZ.

3) Pembahasan pada penelitian ini fokus pada Business Goals: Internal Perspective, pada butiran nomor 11 perihal Lower Process Costs (biaya proses yang rendah) dengan IT Goals yaitu: PO3, AI2, AI5, AI3, AI4, AI7, PO6, DS3, DS7, DS8, DS9, PO5, dan DS6.

\section{AUDIT SISTEM INFORMASI}

Audit atau pemerikasaan memiliki arti luas bermakna untuk mengevaluasi laporan terhadap suatu organisasi, sistem, proses, atau produk. Menurut [1] audit pada dasarnya adalah proses sistematis dan obyektif dalam memperoleh dan mengevaluasi bukti-bukti tindakan ekonomi, guna memberikan pernyataan dan menilai seberapa jauh tindakan ekonomi sudah sesuai dengan kriteria yang berlaku dan mengkomunikasikan hasilnya kepada pihak terkait.

Setiap organisasi memiliki sistem informasi, ada organisasi yang memiliki sistem informasi formal namun juga ada yang tidak. Sistem informasi informal (atau kurang formal) terdiri atas gosip, isu, dan lainnya. Sistem informasi formal adalah sistem informasi yang dikembangkan secara spesifik untuk mendukung jalannya organisasi. Sistem informasi adalah kombinasi antar prosedur kerja, informasi, orang, dan teknologi informasi yang diorganisasikan untuk mencapai tujuan dalam sebuah organisasi. Sistem informasi didefenisikan sebagai organisasi yang menyediakan proses dan informasi yang berguna bagi anggota dan pemangku kepentingannya. Informasi tertentu dapat berupa para pengembangnya, pengguna, pihak manajemen organisasi, konsumen, supplier, dan badan pemerintah [2]. Menurut [3], sistem informasi adalah sekumpulan komponen yang berfungsi mengumpulkan, menyimpan, dan mengolah data dan bertujuan untuk memberi informasi, pengetahuan, dan produk digital, saling bekerja sama untuk mencapai suatu tujuan. Sistem informasi mendatangkan manfaat bagi berbagai pihak terkait, diantaranya adalah perusahaan, perorangan, maupun bagi industri.

Audit sistem informasi adalah audit atas pengendalian internal dari sistem informasi dan cara penggunaan sistem tersebut [4]. Menurut [5], audit sistem informasi merupakan suatu teknik penelitian terhadap sebuah sistem dengan menguraikan komponen-komponen pada sistem tersebut dengan tujuan untuk mempelajari komponen itu sendiri serta keterkaitannya dengan komponen lain yang membentuk sistem sehingga didapat sebuah keputusan atau kesimpulan mengenai sistem tersebut baik itu kelemahan ataupun kelebihan sistem.

\section{3. $\quad$ COBIT 4.1}

Control Objectives for Information and Related Technology (COBIT) adalah suatu kerangka kerja untuk membangun suatu IT Governance [6]. Dengan mengacu pada kerangka kerja COBIT (lihat Gambar 1), suatu organisasi diharapkan mampu menerapkan IT Governance dalam pencapaian tujuannya IT Governance mengintegrasikan cara optimal dari proses perencanaan dan pengorganisasian, pengimplementasian, dukungan serta proses pemantauan kinerja Teknologi Informasi. IT Governance adalah penerapan kebijakan IT didalam organisasi agar penggunaan IT diarahkan sesuai dengan tujuan IT. 
PETIR: Jurnal Pengkajian dan Penerapan Teknik Informatika Vol. 13, No. 1, Maret 2020, P-ISSN 1978-9262, E-ISSN 2655-5018 DOI: https://doi.org/10.33322/petir.v13i1.891

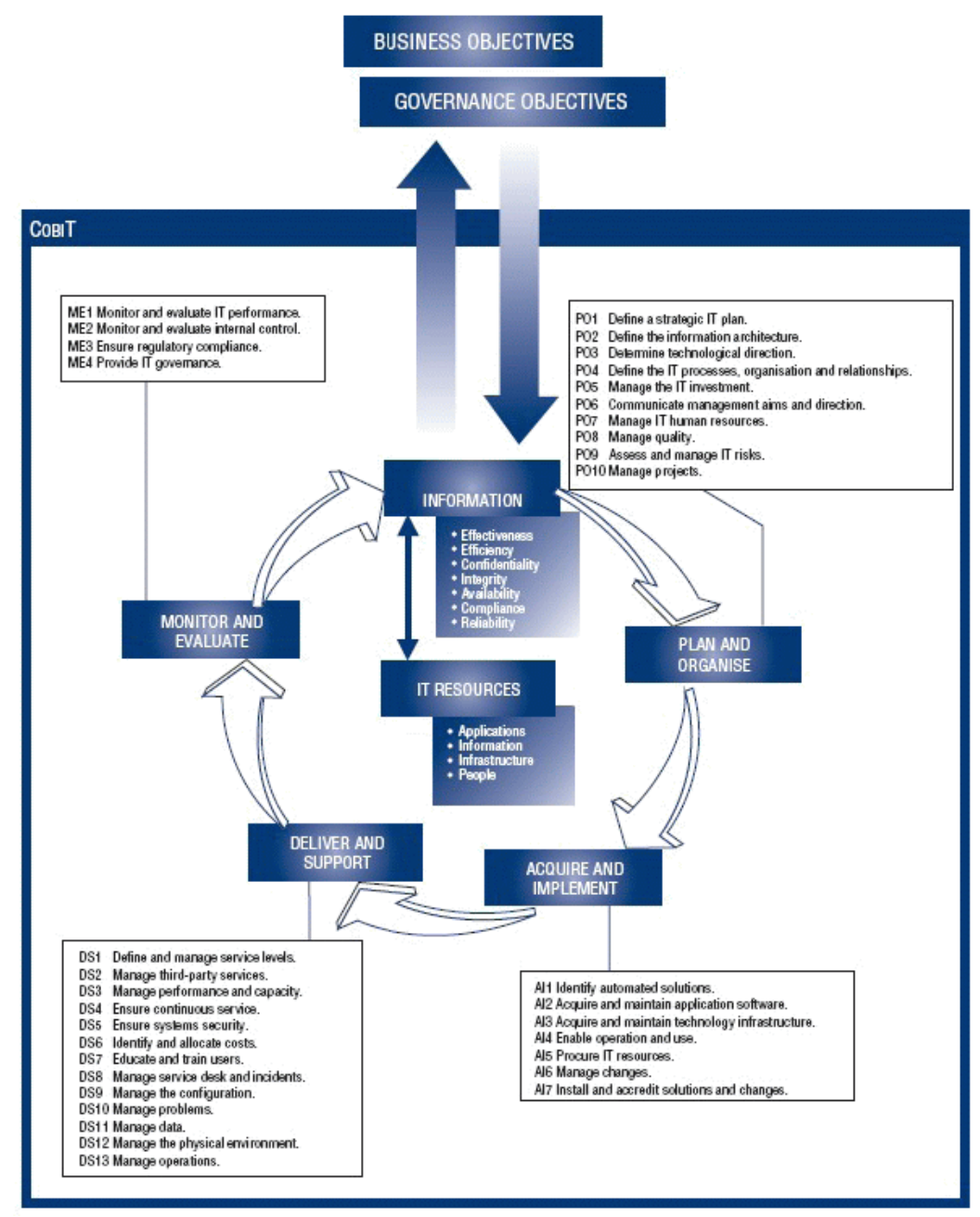

Gambar 1. Kerangka Kerja COBIT 4.1 [6]

Yang menjadi tolak ukur dalam standar COBIT adalah maturity level yang digunakan untuk menentukan sampai mana tingkat proses dan pengelolaan IT tersebut [7]. Berikut ini adalah penjelasan mengenai maturity level yang dipakai:

1) Level 0 (0-0.49) Non-existent - Tidak memiliki proses pengawasan, prosedur untuk memantau efektivitas kontrol internal, ada sedikit kesadaran akan kebutuhan eksternal yang mempengaruhi IT, tidak memahami kekurangan atas proses pengaturan IT.

2) Level 1 (0.50-1.49) Initial/Ad Hoc - Perusahaan mulai menyadari perlunya pengkajian terhadap suatu masalah namun tidak terdapat proses yang standar.

3) Level 2 (1.50-2.49) Repeatable but Intuitive - Prosedur diikuti tetapi masih ada tingkat ketergantungan yang tinggi pada pengetahuan individu. Tidak ada training atau komunikasi secara formal tentang prosedur standar dan tanggung jawabnya jatuh pada individu. Ada ketergantungan yang tinggi pada individu dan sering terjadi error.

4) Level 3 (2.50-3.49) Defined Process - Prosedur distandarisasi tetapi tidak cukup canggih. Telah dilakukan traning dan telah didokumentasikan, tetapi tetap dibutuhkan pelatihan.

5) Level 4 (3.50-4.49) Managed and measurable - terdapat kepatuhan sesuai dengan yang telah ditetapkan sebelumnya dan dapat mengetahui mengenai suatu masalah yang signifikan serta memberikan sebuah pelatihan dan kebutuhan sistem pun ditambahkan kedalam aplikasi dan digunakan secara terpisah. 
PETIR: Jurnal Pengkajian dan Penerapan Teknik Informatika

6) Level 5 (4.50-5.00) Optimized - Penyempitan proses ke tingkat praktek yang baik terjadi dan variasi terus berkurang. Terintegrasinya penggunaan IT dalam otomatisasi alur pekerjaan. Dalam meningkatkan kualiatas IT dengan terdapatnya alat yang membantu meningkatkan efektif dan kualitas proses.

\section{METODOLOGI PENELITIAN}

Tahapan yang dilakukan dalam penelitian dapat dilihat pada Gambar 2 berikut:

1. Identifikasi Proses COBIT

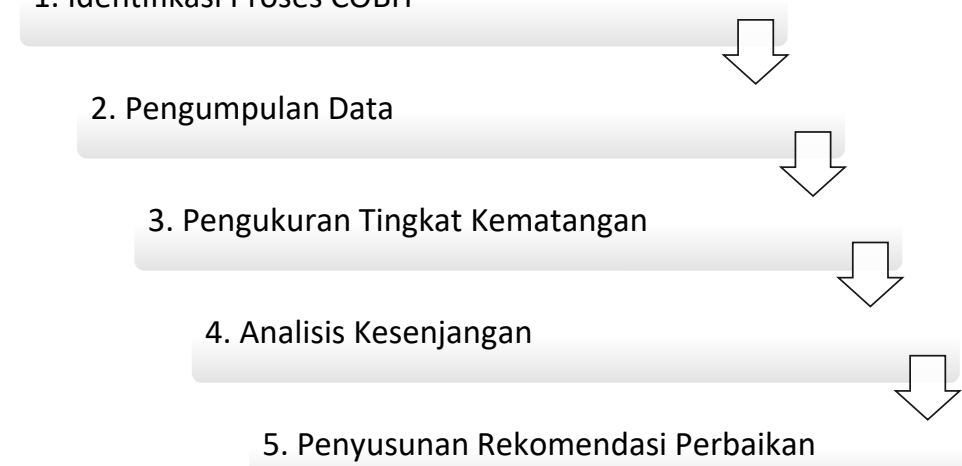

Gambar 2. Metodologi Penelitian

Tahap pertama adalah melakukan identifikasi proses sesuai domain pada COBIT 4.1. Setelah identifikasi proses telah dilakukan, berikutnya adalah melakukan pengumpulan data melalui wawancara dan instrumen kuesioner yang disebarkan kepada para pengguna Key Logistics System. Setelah data terkumpul, dilakukan analisis data untuk mengukur tingkat kematangan sistem. Audit data penelitian dibagi menjadi tingkat kematangan (maturity Level) saat ini dan audit tingkat kematangan yang diharapkan [7]:

\section{1) Audit tingkat kematangan saat ini (as is)}

Berdasarkan data hasil kuesioner dilakukan audit untuk menilai tingkat kematangan saat ini (as is) untuk proses domain yang digunakan. Pada audit tingkat kematangan saat ini dilakukan penilaian terhadap masing-masing aktivitas. Sedangkan untuk hasil jawaban kuesioner tingkat kematangan, akan tersedia 5 pilihan jawaban dengan nilai 0-5. Tingkat kematangan atribut diperoleh dari perhitungan total pilihan jawaban kuisioner dengan rumus dan pembobotan pilihan jawaban sebagai berikut:

$$
\text { Indeks Kematangan }=\frac{\text { Total jawaban } \times \text { Bobot }}{\text { Jumlah soal } \times \text { Jumlah responden }}
$$

\section{2) Audit tingkat kematangan yang diharapkan}

Penilaian tingkat kematangan yang diharapkan (to be) bertujuan untuk memberikan acuan atau standarisasi untuk pengembangan tata kelola IT Perusahaan Ekspedisi XYZ. Tingkat kematangan yang akan menjadi acuan ke depan dalam proses pengawasan dan evaluasi di Perusahaan Ekspedisi XYZ dapat ditentukan dengan melihat faktor sebagai berikut: 
PETIR: Jurnal Pengkajian dan Penerapan Teknik Informatika Vol. 13, No. 1, Maret 2020, P-ISSN 1978-9262, E-ISSN 2655-5018 DOI: https://doi.org/10.33322/petir.v13i1.891

a) Visi, misi, dan tujuan Perusahaan Ekspedisi XYZ.

b) Hasil kuesioner tentang kesadaran pengelolaan.

c) Wawancara dengan pihak pengguna IT Perusahaan Ekspedisi XYZ.

Setelah diperoleh hasil tingkat kematangan saat ini dan yang diharapkan, selanjutnya dilakukan analisis kesenjangan untuk membandingkan tingkat kematangan saat ini dan target. Berdasarkan hasil analisis kesenjangan, langkah terakhir dari penelitian adalah merumuskan rekomendasi perbaikan tingkat kematangan Key Logistics System di masa mendatang.

\section{HASIL DAN PEMBAHASAN}

\subsection{Karakteristik Responden}

Pada penelitian ini metode pengumpulan data menggunakan kuesioner. Dalam hal ini yang menjadi subjek responden adalah staff yang berhubungan langsung menggunakan sistem pada Perusahaan Ekspedisi XYZ. Dikarenakan terbatasnya populasi hanya 26 orang. Dengan demikian kuesioner disebarkan kepada 26 orang dengan jumlah sampel sama dengan populasi yang disebut dengan sampling jenuh. Karakteristik responden berdasarkan jenis kelamin dapat dilihat pada Tabel 1 .

Tabel 1. Frekuensi Responden Berdasarkan Jenis Kelamin

\begin{tabular}{|l|c|c|}
\hline Jenis Kelamin & $\begin{array}{c}\text { Jumlah } \\
\text { Responden }\end{array}$ & $\begin{array}{c}\text { Persentase } \\
(\boldsymbol{\%})\end{array}$ \\
\hline Laki-laki & 9 & 34,6 \\
\hline Perempuan & 17 & 65,4 \\
\hline Total & 26 & 100 \\
\hline
\end{tabular}

Berdasarkan tabel diatas maka terdapat rincian jumlah responden berkelamin pria sebanyak 9 orang atau $34,6 \%$ dan wanita sebanyak 17 orang atau $65,4 \%$.

Berdasarkan usia responden, terdiri atas 6 kategori, yaitu usia 16-20 tahun, 21-25 tahun, 2630 tahun, 31-35 tahun, 40-45 tahundan 50-55 tahun. Berikut karakteristik responden berdasarkan usia seperti pada Tabel 2.

Tabel 2. Frekuensi Responden Berdasarkan Rentang Usia

\begin{tabular}{|c|c|c|}
\hline Usia & $\begin{array}{c}\text { Jumlah } \\
\text { Responden }\end{array}$ & $\begin{array}{c}\text { Persentase } \\
(\boldsymbol{\%})\end{array}$ \\
\hline $\mathbf{1 6 - 2 0}$ & 1 & 3,85 \\
\hline $\mathbf{2 1 - 2 5}$ & 13 & 50,05 \\
\hline $\mathbf{2 6 - 3 0}$ & 5 & 19,2 \\
\hline $\mathbf{3 1 - 3 5}$ & 2 & 7,7 \\
\hline $\mathbf{4 0 - 4 5}$ & 3 & 11,5 \\
\hline $\mathbf{4 6 - 5 0}$ & 0 & 0 \\
\hline $\mathbf{5 1 - 5 5}$ & 2 & 7,7 \\
\hline Total & 26 & 100 \\
\hline
\end{tabular}

Berdasarkan Tabel 2 untuk variabel usia disimpulkan bahwa responden yang berusia 16 sampai 20 sebanyak 1 orang atau 3,85\%, responden yang berusia 21 sampai 25 sebanyak 13 orang atau $50,05 \%$, responden yang berusia 26 sampai 30 sebanyak 5 orang atau 19,2\%, responden 31 sampai 35 sebanyak 2 orang atau 7,7\%, responden berusia 40 sampai 45 sebanyak 3 orang atau $11,5 \%$, dan responden berusia 50 sampai 55 sebanyak 2 orang atau $7,7 \%$. 
PETIR: Jurnal Pengkajian dan Penerapan Teknik Informatika Vol. 13, No. 1, Maret 2020, P-ISSN 1978-9262, E-ISSN 2655-5018 DOI: https://doi.org/10.33322/petir.v13i1.891

\subsection{Interpretasi Hasil Penelitian}

Dalam tahap ini dilakukan penilaian terhadapat kuisioner yang tersebar, untuk mengetahui tingkat kematangan yang disesuaikan dengan model kematangan COBIT 4.1. Tingkat kematangan yang didapat menunjukan ada di level berapakan tingkat kematangan Key Logistics System pada Perusahaan Ekspedisi XYZ. Ada perhitungan tingkat kematangan yang dapat menghasilakan seberapa besar tingkat kematangan sistem yang digunakan.

Tingkat kematangan diperoleh dari hasil perhitungan kuesioner. Pernyataan dalam kuesioner diambil dari pernyataan yang sudah ada didalam model tingkat kematangan COBIT 4.1. Setiap kalimat terdapat deskripsi model tingkat kematangan COBIT 4.1 sesuai dengan proses IT terkait yang dipecah menjadi kalimat sederhana. Untuk masing-masing pernyataan, tersedia lima jawaban sesuai dengan tingkat kesetujuan responden terhadap masing-masing pernyataan yang diberikan, yaitu tidak, ragu-ragu mendekati tidak, ragu-ragu, ragu-ragu mendekati ya, dan ya. Setiap jawaban diberi bobot nilai atau compliance, seperti tertera dalam Tabel 3.

Tabel 3. Bobot (compliance) Nilai Jawaban

\begin{tabular}{|l|c|}
\hline \multicolumn{1}{|c|}{ Jawaban } & Bobot \\
\hline Tidak (T) & 0 \\
\hline Ragu-ragu Mendekati Tidak (RMT) & 0,25 \\
\hline Ragu-ragu (RR) & 0,5 \\
\hline Ragu-ragu Mendekati Ya (RMY) & 0,75 \\
\hline Ya (Y) & 1 \\
\hline
\end{tabular}

Pada tiap-tiap proses level (L), nilai total compliance didapat dari responden menjawab pernyataan setiap kalimat, lalu dikalikan dengan nilai bobot yang sudah ditentukan sebelumnya. Untuk hasil score didapatkan dari hasil compliance dibagi jumlah responden yang menjawab secara penuh pernyataan dalam kuesioner yaitu 26 orang. Sedangkan hasil dari SK didapat dari pembagian jumlah kalimat dengan score. Untuk nilai dari normalisasi dilakukan dengan membagi nilai masingmasing tingkat (SK) dengan nilai total (SK). Setelah masing-masing dinormalisasikan, langkah terakhir dalam perhitungan nilai maturity level adalah menghitung kontribusi masing-masing level, setelah itu dijumlahkan. Tingkat kematangan Key Logistics System dapat dilihat pada Tabel 4.

Tabel 4. Tingkat Kematangan Key Logistics System

\begin{tabular}{|l|c|c|c|}
\hline Proses IT & $\begin{array}{c}\text { Skor } \\
\text { Kematangan }\end{array}$ & $\begin{array}{c}\text { Tingkat } \\
\text { Kematangan } \\
\mathbf{1 - 5}\end{array}$ & Keterangan \\
\hline PO3 & 3.60 & 4 & Managed \\
\hline PO5 & 2.99 & 3 & Defined \\
\hline PO6 & 3.55 & 4 & Managed \\
\hline AI2 & 3.46 & 3 & Defined \\
\hline AI3 & 3.50 & 4 & Managed \\
\hline AI4 & 3.60 & 4 & Managed \\
\hline AI5 & 3.44 & 3 & Defined \\
\hline AI7 & 3.64 & 4 & Managed \\
\hline DS3 & 3.54 & 4 & Managed \\
\hline DS6 & 3.60 & 4 & Managed \\
\hline DS7 & 3.54 & 4 & Managed \\
\hline
\end{tabular}


PETIR: Jurnal Pengkajian dan Penerapan Teknik Informatika Vol. 13, No. 1, Maret 2020, P-ISSN 1978-9262, E-ISSN 2655-5018 DOI: https://doi.org/10.33322/petir.v13i1.891

\begin{tabular}{|l|c|c|c|}
\hline DS8 & 3.60 & 4 & Managed \\
\hline DS9 & 3.50 & 4 & Managed \\
\hline Rata-rata & 3.504 & 4 & Managed \\
\hline
\end{tabular}

Tingkat kematangan yang ditargetkan adalah 4 dan secara best practice adalah 5. Kesenjangan tingkat kematangan dapat dilihat pada grafik sarang laba-laba pada Gambar 3.

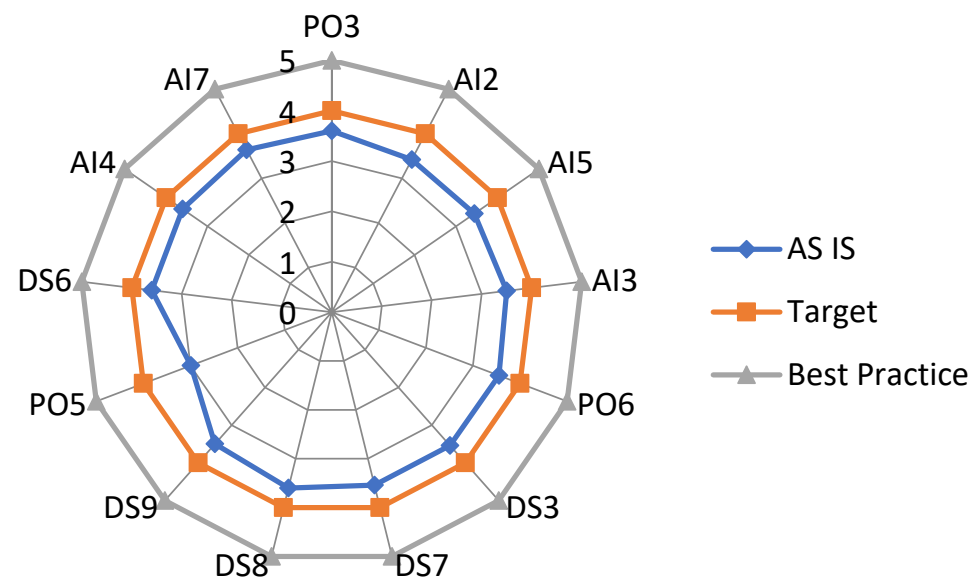

Gambar 3. Grafik Laba-laba Tingkat Kematangan Key Logistics System

\subsection{Rekomendasi Hasil Penelitian}

Ada beberapa rekomendasi untuk Key Logistics System pada Perusahaan Ekspedisi XYZ sesuai dengan proses IT yang telah diaudit. Rekomendasi hasil audit dapat dilihat pada Tabel 5.

Tabel 5. Rekomendasi Proses IT

\begin{tabular}{cl}
$\begin{array}{c}\text { Proses } \\
\text { IT }\end{array}$ & \multicolumn{1}{c}{ Rekomendasi } \\
\hline PO3 & $\begin{array}{l}\text { Perencanaan pengembangan Key Logistics System hendaknya mempertimbangkan risiko dan } \\
\text { keselarasan dengan strategi bisnis perusahaan }\end{array}$ \\
\hline PO5 & $\begin{array}{l}\text { Pengembangan Key Logistics System hendaknya mempertimbangkan perhitungan investasi TI } \\
\text { dengan membandingkan antara biaya dan manfaat }\end{array}$ \\
\hline PO6 & $\begin{array}{l}\text { Perlu dilakukan perbaikan kebijakan tata kelola TI yang telah ada dengan melampirkan prosedur } \\
\text { yang terstruktur dan pemberian tanggung jawab }\end{array}$ \\
\hline AI2 & $\begin{array}{l}\text { Pemeliharaan aplikasi dilakukan lebih terencana, terdokumentasi, terjadwal, dan terkoordinasi } \\
\text { dengan manajemen TI }\end{array}$ \\
\hline AI3 & $\begin{array}{l}\text { Pemeliharaan infrastruktur TI dilakukan lebih terencana, terdokumentasi, terjadwal, dan } \\
\text { terkoordinasi dengan manajemen TI }\end{array}$ \\
\hline AI4 & $\begin{array}{l}\text { Perlu dilakukan evaluasi terhadap implementasi standar operasional dan penggunaan aplikasi } \\
\text { Key Logistics System }\end{array}$ \\
\hline AI7 & $\begin{array}{l}\text { Pengadaan sumber daya TI harus diselaraskan dengan rencanan dan kebutuhan sumber daya } \\
\text { yang ada di perusahaan }\end{array}$ \\
\hline DS3 & Perlu dikembangkan metode formal dalam instalasi aplikasi atau migrasi teknologi \\
\hline DS6 & $\begin{array}{l}\text { Standar alokasi biaya perlu diformalkan untuk mendukung proses pengadaan infrastruktur } \\
\text { teknologi dan aplikasi }\end{array}$ \\
\hline
\end{tabular}


PETIR: Jurnal Pengkajian dan Penerapan Teknik Informatika Vol. 13, No. 1, Maret 2020, P-ISSN 1978-9262, E-ISSN 2655-5018 DOI: https://doi.org/10.33322/petir.v13i1.891

\begin{tabular}{cl}
$\begin{array}{c}\text { Proses } \\
\text { IT }\end{array}$ & Rekomendasi \\
\hline DS7 & $\begin{array}{l}\text { Perlu dilakukan program pelatihan dan pendidikan pengguna agar aplikasi dapat dimantaafkan } \\
\text { secara maksimal untuk memberikan manfaat bagi perusahaan }\end{array}$ \\
\hline DS8 & Hendaknya dilakukan peningkaan layanan dan insiden yang dilakukan oleh unit IT perusahaan \\
\hline DS9 & $\begin{array}{l}\text { Manajemen konfigurasi perlu ditingkatkan dan dievaluasi secara berkala untuk memastikan } \\
\text { aplikasi dapat dioperasikan secara baik }\end{array}$ \\
\hline
\end{tabular}

\section{KESIMPULAN DAN SARAN}

\subsection{Kesimpulan}

Audit menggunakan COBIT4.1 sebagai standar penilaian ini telah memperlihatkan nilai tingkat kematangan proses Key Logistics System pada Perusahaan Ekspedisi XYZ. Ada beberapa kesimpulan audit dari proses IT, yaitu:

1) Berdasarkan hasil penelitian tingkat kematangan IT Goals, diperoleh bahwa proses PO5, AI2, dan AI5 berada pada level 3 (defined), sedangkan PO3, AI3, AI4, AI7, PO6, DS3, DS7, DS8, DS9, dan DS6 berada pada level 4 (managed).

2) Nilai rata-rata tingkat kematangan 3.50 atau berada di level 4 yang menandakan bahwa terdapat kepatuhan sesuai dengan yang telah ditetapkan sebelumnya dan dapat mengetahui mengenai suatu masalah yang signifikan serta memberikan sebuah pelatihan dan kebutuhan sistem pun ditambahkan kedalam aplikasi dan digunakan secara terpisah

3) Pada level 4 ini, proses TI pada Key Logistics System sudah dijalankan dan sebagian sudah distandarisasi.

\subsection{Saran}

Berikut beberapa saran yang dapat diberikan untuk pegembangan penelitian selanjutnya antara lain:

1) Diharapkan peneliti lain dapat melakukan semua tahap yang ada pada audit sistem informasi dalam melakukan penilaian terhadap sistem informasi yang digunakan.

2) Penelitian yang lebih lanjut dapat dengan menambahkan jumlah sampel.

\section{DAFTAR PUSTAKA}

[1] W. Puspitasari, "Audit Tata Kelola Teknologi Informasi Menggunakan Framework COBIT 4.1 dengan Model Maturity Level," Teknologi, 2015.

[2] S. S., Metodologi Pengembangan Sistem, Jakarta: Indeks, 2017.

[3] K. C. Laudon and J. P. Laudon, Sistem Informasi Manajemen: Mengelola Perusahaan Digital, Jakarta: Salemba Empat, 2018.

[4] F. Zamzami, I. A. Faiz and Mukhlis, Audit Internal Konsep dan Praktik Sesuai International Standards for the Professional Practice of Internal Auditing 2013, Yogyakarta: Gajah Mada University Press, 2018.

[5] S. Mulyani, Analisis dan Perancangan Sistem Informasi Manajemen Keuangan Daerah: Notasi Pemodelan Unified Modeling Language (UML), Bandung: Abdi Sistematika, 2016.

[6] IT Governance Institute, COBIT 4.1, IT Governance Institute, 2007.

[7] F. A. Johanes and C. Kevin, Audit Menggunakan COBIT 4.1 dan COBIT 5 dengan Case Study, Yogyakarta: Teknosain, 2018. 